\title{
O PROCESSO DE DECISÃO DE COMPRA DO CONSUMIDOR BRASILEIRO: FATO OU FICÇÃO?
}

\section{THE DECISION MAKING PROCESS OF BUYING THE BRAZILIAN CONSUMER: FACT OR FICTION?}

\author{
Orlando Isidoro Loureiro \\ Mestre em Administração \\ Pontifícia Universidade Católica, São Paulo, Brasil
}

RESUMO

O debate a respeito do modelo de decisão de compra do consumidor pode ser dividido em dois blocos. O primeiro é composto por autores que consideram que o consumidor segue um roteiro para tomar decisões de compra, o segundo bloco é composto por autores que não reconhecem o roteiro, e sim, o nível de envolvimento com a compra. Este artigo objetivou confrontar essas linhas de pensamento e apresentar os resultados de uma pesquisa empírica.

Palavras chave: consumidor; tomada de decisão; modelo.

\begin{abstract}
The debate about the model of consumer buying decision can be divided into two blocs. The first bloc is comprised of authors that consider the fact that consumers follow a schedule in order to make purchases decisions. The second bloc is comprised of the authors that do not recognize any steps, but rather, the level of involvement with the purchase. This article had the objective to confront these lines of thinking and present the results from an empirical research.
\end{abstract}

Keywords: consumer; decision making; model 


\section{1- INTRODUÇÃO}

Entre as várias atividades cotidianas do ser humano encontram-se a de consumir. Não bastasse o fato de se tratar de uma atividade inerente ao ser humano, na última década, especificamente no Brasil, o incentivo ao consumo foi o ponto focal do Governo Lula. E o povo brasileiro respondeu à altura, como pode ser comprovado por meio dos dados disponibilizados pelo Instituto Brasileiro de Geografia e Estatística (IGBE), quando informa que a Pesquisa de Orçamento Familiar (POF) 2008-200 9 apontou o valor de R\$2.626,31, como estimativa da despesa total média mensal familiar no país, sendo que desse valor, $81,3 \%$ são despesas de consumo (LIMEIRA, 2008; IBGE, 2012) .

Certamente não foi sempre assim, pois recuando no tempo, por exemplo, antes do século XX, as bases do relacionamento entre fornecedor e consumidor não eram ajustadas de maneira a focar a obtenção de benéficos para as partes envolvidas na negociação. O poder de barganha estava nas mãos daqueles que vendiam os bens e serviços. A contestação do consumidor ao sistema estabelecido na época não tinha efeito, pelo contrário, era rechaçada com veemência (VOLPI, 2007).

No entanto, o cenário em que os intermediários de produtos tinham o poder de barganha modificou-se em função do surgimento de um a nova economia em escala global, a partir do último quartel do século XX. Esta nova economia possui três características: o informacionalismo, pois a produtividade e a competitividade dos que participam dessa econômica, sejam empresas, regiões ou nações, é função de sua capacidade de gerar, processar e aplicar eficientemente a informação baseada em conhecimentos; a globalização, pois as principais atividades produtivas, o consumo e a circulação organizam-se em escala global, seja diretamente ou por meio de uma rede de conexões entre agentes econômicos; e funciona em rede, isto porque a produtividade é gerada e a concorrência acontece em uma rede global de interação entre redes empresariais (CASTELLS, 2002).

Essa nova economia tem sua formatação em fases diferentes nos blocos de nações dos vários continentes, portanto, não é linear como acontecimento, mas no Brasil o cenário descrito por Castells (2002) é uma realidade em franca evolução. E, focando a parcela pertinente ao consumidor brasileiro e seu comportamento de consumo, as mudanças no cenário global habilitou-o a ser mais crítico e exigente, apoiando-se com mais pertinência no código de defesa do consumidor. Embora o Código Comercial de 1840, em seus Artigos 629 e 632 já estabelecia os direitos e as obrigações dos passageiros de embarcações, outros acontecimentos nas décadas de 1930, 1950 e 1960 contribuiriam para que a década de 1970 contemplasse um marco no país, a criação do Grupo Executivo de Proteção ao Consumidor, o PROCON. Foi criado em 1976, pelo Governo do Estado de São Paulo como o primeiro órgão público de proteção ao consumidor (PROCON, 2012).

Paralelamente aos acontecimentos jurídicos de proteção ao consumidor, o crescimento da concorrência por conta da evolução tecnológica, os efeitos dos programas de governo dos últimos vinte anos, foram fundamentais na inserção da parcela populacional da base da pirâmide brasileira no consumo, bem como no fortalecimento das demais classes sociais.

O consumidor, no caso do presente artigo, o brasileiro, continuará evoluindo e enfrentando desafios, dentre os quais está o de compreender e assimilar os cuidados com o ambiente local e global. Seu comportamento como consumidor não está mais limitado ao ato da compra, mas ao descarte de resíduos. Proibição d e sacolas plásticas em supermercados, o descarte de pilhas, bateria de celular, óleo vegeta 1 , enfim, o lixo reciclável, ainda são comportamentos, apropriadamente incorporados pela população, o que pode ser comprovado no período de chuvas no país quando se observa as galerias e bueiros repletos de embalagens e objetos (sofás, móveis, eletroeletrônicos, roupas etc.) de diversos tipos e cores (DETRITOS..., 2010).

As empresas, por sua vez, diante da dinâmica do mercado e a voraz concorrência, buscam ser responsiva tanto às demandas ambientais como às necessidades e desejos dos 
consumidores. E nessa guerra pelos consumidores residem às estratégias de segmentação de mercado, produto, preço, marca e distribuição, apenas para citar algumas.

Nesse processo de evolução do consumidor as empresas têm enfrentado uma árdua tarefa que é conhecer o seu público e entregar um pacote de soluções por meio de produtos. E não bastassem entregar os produtos, as empresas se interessam em saber como foram descartados os resíduos resultantes da obtenção, us o e consumo do que foi vendido ao consumidor com a finalidade de ampliar seu conhecimento a respeito do comportamento de seu público.

Uma das maneiras de se conhecer o comportamento do consumidor é por meio do estudo do processo de tomada de decisão de compra e os debates em torno dele, investigado há décadas por vários autores, entre eles Nicosia1966),( Howard e Sheth (1969), Giglio (2003), Blackwell, Miniard e Engel (2005) e Limeira (2008), e que será objeto de análise do próximo item do presente artigo.

\section{2 - O PROCESSO DE DECISÃO DO CONSUMIDOR}

Compreender o comportamento humano requer mais do que interesse ou curiosidade acadêmica. Além do método envolve a abordagem a ser adotada pelo pesquisador. Nas palavras de Cervo, Bervian e Silva, em sentido geral: "método é a ordem que se deve impor aos diferentes processos necessários para atingir certo fim ou um resultado desejado".

(CERVO; BERVIAN; SILVA, 2007, p. 27)

Quanto à abordagem, quando se fala do modelo de processo de decisão do consumidor, Blackwell e outros fazem referência a um "mapa rodoviário das mentes dos consumidores" como sendo apropriado para a compreensão da tomada de decisão de compra (BLACKWELL et al., 2005, p. 73). Uma abordagem pragmática de cunho positivista do processo pode ser observada no modelo proposto pelos autores (Figura 1)

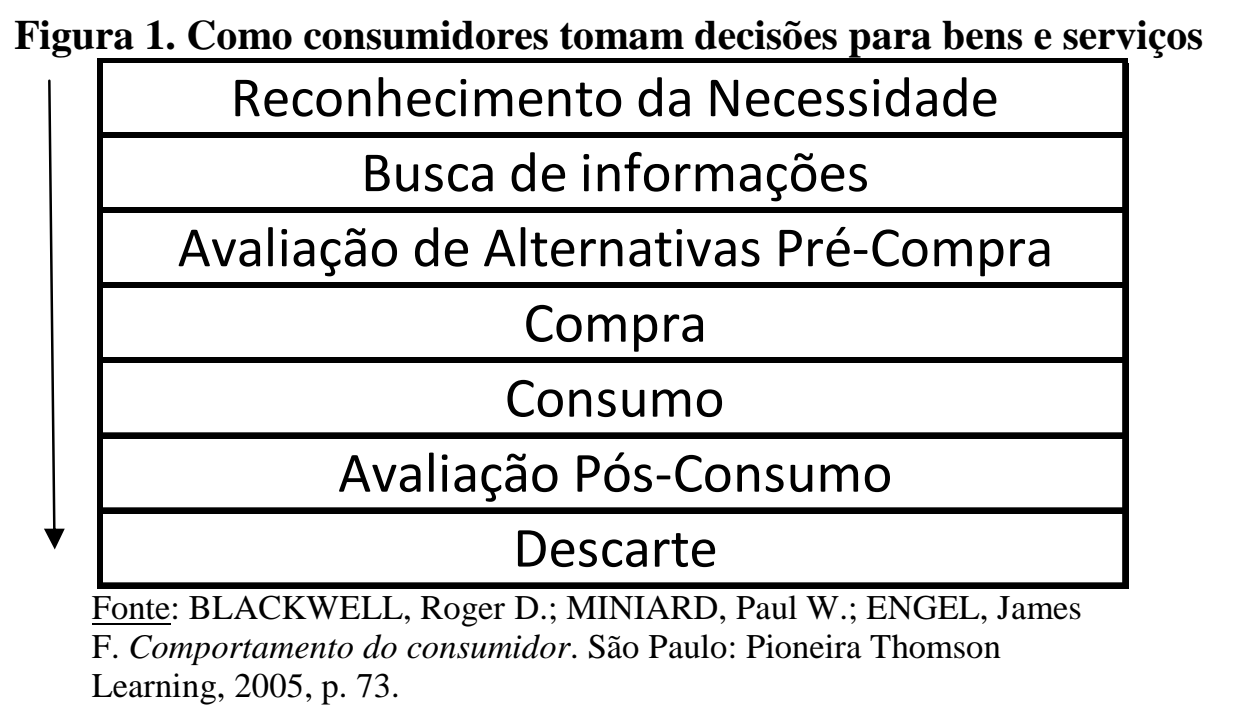

Em relação à construção de modelos de decisão de compra do consumidor, Nicosia (1966) pode ser considerado um pioneiro por ofertar os primeiros esforços resultantes de pesquisas das ciências sociais e da economia. A Figura 2 representa versão simplificada de seu trabalho.

O modelo de Nicosia (1966) propõe que o consumidor irá pesquisar e avaliar a informação obtida como resultado de sua exposição à mensagem da empresa, quase sempre publicitária. Assim, espera-se que as características da empresa, de acordo com o que foi manifestada na mensagem (subcampo 1), se combinem com aquelas já possuídas pelo consumidor (subcampo 2), para que em caso de exposição, resulte em uma atitude. A próxima etapa é a atividade de investigação e avaliação das relações "meio-fins" (campo 2), de maneira a associar as marcas disponibilizadas com as expectativas sugeridas das atitudes. 
Espera-se nesse momento do processo que surja uma motivação específica para uma marca, onde os efeitos dos fatores situacionais (propaganda, ambiente físico e social, tempo etc.) transformem-se ou não em um ato de compra (campo 3). A etapa seguinte é o consumo e o armazenamento do produto comprado resultando, tanto para o consumidor quanto para a empresa, em uma experiência (campo 4), a qual modificará as características iniciais e retornará, desta maneira, ao ponto de partida (KARSAKLIAN, 2008).

\section{Figura 2. The Comprehensive Scheme: A Summary Flow Chart}

Campo 1: Da fonte da mensagem à atitude do consumidor

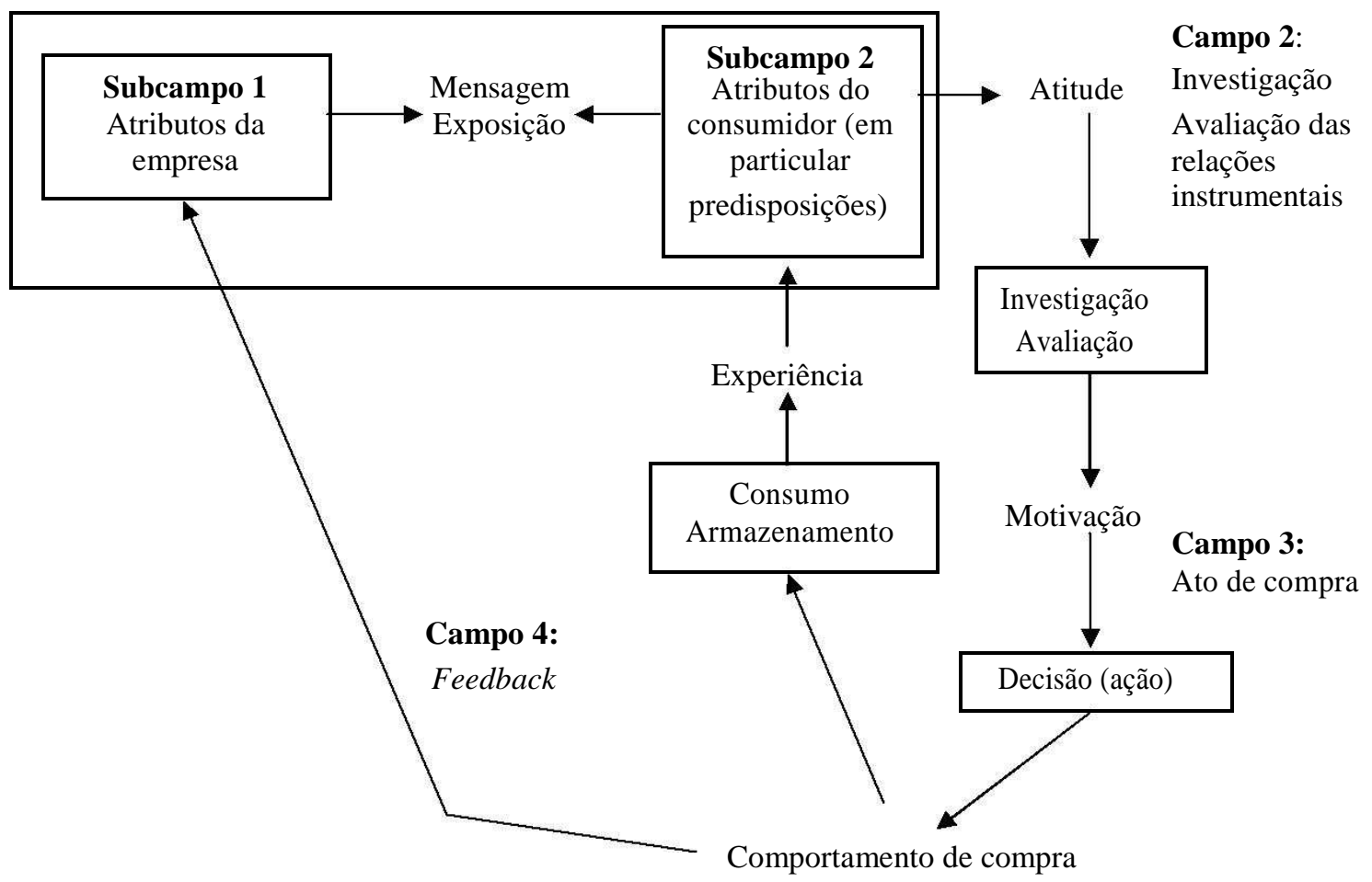

Fonte: NICOSIA, Francesco M. Consumer decision processes: marketing and advertising implications. Englewood Cliffs, New Jersey: Prentice-Hall, 1966, p. 156.

O modelo apresentado por Howard and Sheth (1969), Figura 3, é considerado por Karsaklian (2008) como o mais completo e o mais significativo resultado das pesquisas realizadas neste campo. O modelo segue a escola behaviorista e pretende explicar a maneira como o consumidor transforma os estímulos externos (entradas) em decisões de compra (saídas).

É possível perceber quando se compara o modelo de Howard e Sheth (1969) com a proposta de Blackwell e outros (2005), que o primeiro enfatiza a primeira fase do processo do segundo, ou seja, o reconhecimento da necessidade. Esta comparação permite justificar o fato de o modelo de Howard e Sheth (1969) seguir a escola behaviorista. Isto é dito, pois embora outros autores propõe modelos de decisão de compra, e mesmo enfatizando determinada etapa, ainda assim eles seguiram a mesma ideia proposta por Nicosia (1966), o que demonstra a linearidade das etapas, ou conforme Olshavsky e Granbois (1979) referem-se ao refinamento do conceito do comportamento de resposta rotinizada. 
Figura 3. Resumo do modelo de Howard e Sheth, 1969.

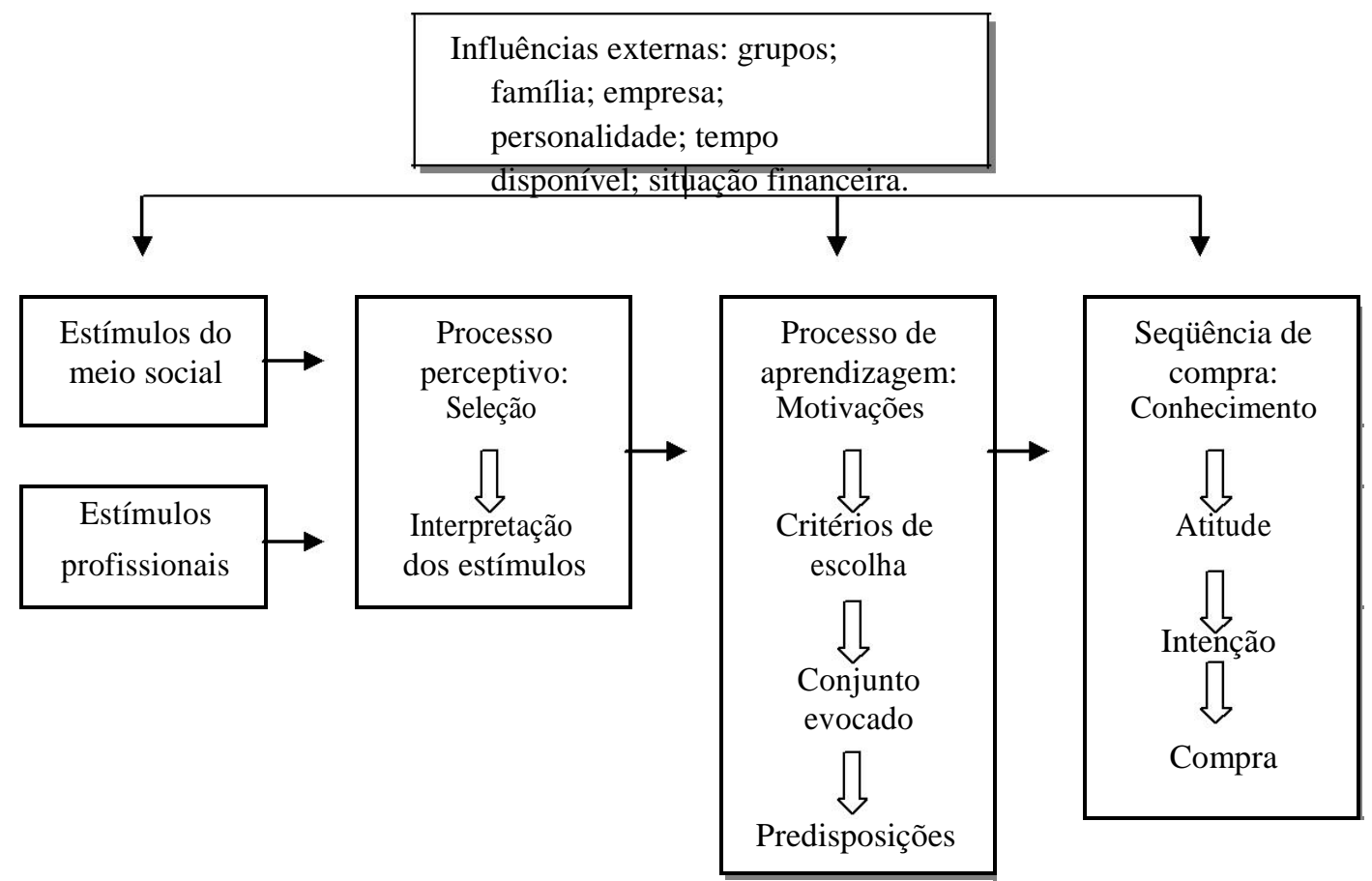

Fonte: GIGLIO, Ernesto M. O comportamento do consumidor. 2. ed. rev. e ampl. São Paulo: Pioneira Thomson Learning, 2003, p. 106.

Praticamente todo trabalho a respeito do comportamento do consumidor inclui um modelo de fluxograma a respeito do processo de decisão do consumidor (Figura 4).

Figura 4. Fluxograma genérico do processo de decisão do consumidor

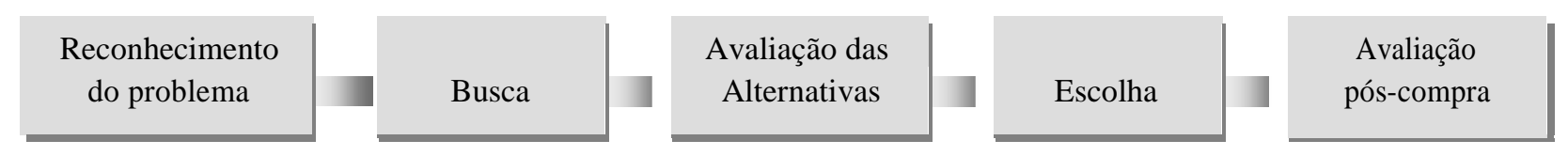

Fonte: MOWEN, John C.; MINOR, Michael S. Comportamento do consumidor. São Paulo: Prentice-Hall, 2003, p. 192.

Portanto, os modelos de tomada de decisão de compra do consumidor, que obedecem a uma estrutura de fluxograma, ou semelhantes aos apresentados neste artigo refletiram, conforme Mowen e Minor (2003), a visão dos pesquisa dores desde o século XVIII até meados da década de 1970, de que as pessoas se moviam linearmente ao longo dos estágios que compõe os modelos esboçados pelas figuras de 1 a 4 .

No entanto, a partir do final da década de 1970, os autores começaram a questionar o fato de que todas as compras são resultantes de um processo apurado e analítico. Entre esses autores estão Richard W. Olshavsky e Donald H. Granbois, que escreveram o artigo "Consumer decision making: fact or fiction?". Neste texto, argumentam que em muitas ocasiões os consumidores não adotam qualquer processo de tomada de decisão antes de efetuar a compra. Afirmam ainda que nunca ocorre um processo de decisão para muitas compras, mesmo que seja a primeira para determinado produto. O trabalho de Olshavsky e Granbois (1979) está fundamentado, também, nas ideias de Kassarjian (1978).

Em 1977, Harold H. Kassarjian, então presidente da Association for Consumer Research, em discurso, levantou a possibilidade de que os autores de trabalhos na área de comportamento do consumidor estavam atribuindo o processo de escolha em situações, onde não ocorria qualquer processo de escolha. $\mathrm{O}$ grau de importância atribuído às marcas, embalagem e processamento de informações, por parte de profissionais e pesquisadores de 
mercado, os têm levado ao exagero na projeção desse comportamento no consumidor.

Diferentemente da perspectiva tradicional da tomada de decisão, (abordagem na qual os consumidores passam de maneira linear por todos os estágios do processo de decisão em situações de altos níveis de processamento de informação), a perspectiva experimental considera que os consumidores sentem e pensam. Esta abordagem propõe que o indivíduo consome vários tipos de produtos em função das sensações, sentimentos, imagens e emoções geradas por eles (LAWSON, 1997; MOWEN; MINOR, 2003).

Por outro lado, a perspectiva da influência comportamental envolverá as evidências físicas como forma de gerar no consumidor as respostas desejadas. Apesar de serem controversas, as perspectivas da influência comportamental e a perspectiva experimental, contribuem na discussão a respeito da riqueza do comportamento do consumidor, uma vez que apenas a formação de crenças e o processamento racional de informação não são suficientes para tal debate (HOFFMAN; BATESON, 2003; MOWEN; MINOR, 2003).

Kassarjian (1978) considerou em seu discurso, o que para ele eram dois problemas: o antropomorfismo e a parcimônia. O primeiro referia- se ao fato dos pesquisadores presumirem que os rótulos são lidos, os produtos comparados, o s preços averiguados; portanto, uma decisão racional é tomada, sendo que usualmente não funciona desta forma. O segundo trata das teorias que, segundo o autor, tornaram-se complexas na tentativa de compreender, explicar e predizer o comportamento do consumidor.

No entanto, Kassarjian (1978) não apresentou qualquer evidência como suporte aos seus argumentos. Neste ponto é que reside a proposta da presente pesquisa. Se, por um lado, os modelos de tomada de decisão têm sido objeto de estudos por décadas, o que pode ser comprovado pelo volume de produção acadêmica por meio de artigos e livros, por outro, os argumentos contrários a esses modelos, não ofertaram produção acadêmica relevante no Brasil, sendo este fato comprovado por meio do uso de palavras-chave em base de dados eletrônicas.

Portanto, no sentido de contribuir com este capítulo do campo do comportamento do consumidor, o autor do presente artigo desenvolveu uma pesquisa com a finalidade de obter elementos que ratifiquem a posição dos autores que sustentam que o consumidor é racional, e que segue um processo linear em sua tomada de decisão ou ampliar a corrente dos que afirmam que os pesquisadores utilizam-se do antropomorfismo, conforme sugerido por Kassarjian (1978), atribuindo um processo linear de escolha ao consumidor, mesmo em ocasiões que não ocorrem qualquer processo de escol ha.

\section{3 - METODOLOGIA}

Tratou-se de uma pesquisa survey, com a finalidade de se coletar dados primários a partir de indivíduos. E, um dos métodos de coleta de dados desse tipo de pesquisa é o questionário. (HAIR et alii, 2005).

Quanto aos propósitos da pesquisa survey, Pinnsoneault e Kraemer (1993) mencionam três: explanatório, exploratório e descritivo. Considerando que a presente pesquisa objetivou discutir a posição de autores em relação ao modelo de decisão de compra do consumidor, e para tanto procurou familiarizar-se com o tema, identificando os conceitos iniciais envolvidos, e descrever as opiniões e atitudes expressadas pela população pesquisada, os propósitos da pesquisa survey atenderam às necessidades do autor deste trabalho.

\section{População e Amostra}

A pesquisa foi realizada com alunos do curso de Administração de Empresas e Curso Tecnológico de Marketing, em uma Instituição de Ensino Superior da cidade de Atibaia. O total de estudantes desses cursos é de aproximadamente 390 alunos. 
Considerando que essa faculdade recebe alunos das cidades de seu entorno, foi possível mapear, por meio do questionário as cidades representadas por alunos que responderam o questionário, embora não equitativamente em número de respondentes. As seis cidades foram: Atibaia, Piracaia, Bom Jesus dos Perdões, Bragança Paulista, Joanópolis e Nazaré Paulista.

O Estado de São Paulo é dividido em 15 mesorregiões ou Regiões Administrativas (RA). Essa divisão foi criada pelo IBGE para fins estatísticos. A pesquisa foi realizada na Região 12 do estado, a qual é composta por 90 cidades dentre as quais estão as 6 cidades pesquisadas.

Foram distribuídos 390 questionários, e 166 foram respondidos, sendo 83 do sexo feminino e 83 do sexo masculino. O questionário era composto de nove questões, sendo três questões intensidade (Escala Likert), cinco fechada s e uma aberta (MARTINS; DONAIRE, 1988).

\section{4 - APRESENTAÇÃO E INTERPRETAÇÃO DOS RESULTADOS}

O questionário apresentou, na primeira questão, cinco categorias de produtos: vestuário, alimentação, higiene pessoal, moradia e automóvel. Também, uma opção "outros", mas que não deveria ser especificado. A finalidade desta questão fechada foi focar o benefício central do produto, o que diminuiria a preocupação com variáveis do tipo, marca e modelo. $\mathrm{O}$ produto adquirido poderia ser para uso próprio ou p ara presentear outra pessoa.

Nestas categorias foram compreendidas três classes de produtos: de conveniência (alimentação e higiene pessoal), compra comparada (vestuário) e compra de especialidade (moradia e automóvel). Produtos que os respondentes tivessem comprado nos últimos 30 dias. Aqueles que não atenderam a essa condição não fizeram parte de pesquisa. Foi em função da primeira questão que as demais foram desenvolvidas (KOTLER, 2003, p. 207).

Desta maneira, a segunda questão (de intensidade) pretendeu verificar o grau de envolvimento do respondente na compra do produto mencionado na primeira questão. Não fez parte do escopo desta pesquisa conhecer o envolvimento do respondente na mesma perspectiva tratada por Muncy e Hunt (1984) quando abordaram os cinco tipos de envolvimento (ego, compromisso, comunicação, compra e resposta (ou reação)). A finalidade foi saber do respondente com que intensidade ele representou seu envolvimento com a compra.

De acordo com Blackwell e outros (2005), o reconhecimento da necessidade ou desejo do indivíduo pode ser entendido como seu grau de discrepância entre o estado atual e o estado desejado. No entanto, os autores não delimitam as fronteiras que correspondem ao nível de suficiência ou insuficiência para afirmar que a necessidade ou desejo de determinado produto foi ou não estabelecida.

Por isso, o autor do presente artigo propôs para esta pesquisa que o respondente informasse por meio de escalas de intensidade, o quanto ele se sentiu ou não envolvido na compra.

A terceira questão (fechada) procurou saber o quão importante é a obtenção de informações por parte dos respondentes em relação a o produto mencionado. A quarta questão (de intensidade) procurou compreender o grau de satisfação do respondente com o volume de informações obtidas para a aquisição do produto.

A quinta questão (fechada) teve a proposta de sabe $\mathrm{r}$ se o respondente considerava importante avaliar alternativas do produto pretendido. A sexta questão (de intensidade) tratou do grau de satisfação do respondente em relação à quantidade de alternativas referentes ao produto adquirido.

$\mathrm{Na}$ sétima questão (fechada) foram apresentadas cinco alternativas, dentre as quais apenas uma deveria ser escolhida como sendo a mais importante na tomada de decisão de compra do produto mencionado pelo respondente na primeira questão. São elas: informações, alternativas, preço, disponibilidade e tempo de entrega. 
A oitava questão (fechada) referiu-se ao modelo ge nérico de decisão de compra do consumidor. $\mathrm{O}$ respondente foi questionado a respeito da utilização, ou não, de um roteiro prévio para o processo de compra do produto mencionado na primeira questão. Aos respondentes que afirmaram utilizar algum roteiro foi solicitado, na oitava questão (aberta) que descrevessem os passos que utilizaram.

\section{5 - DISCUSSÃO DOS RESULTADOS}

As categorias de produtos propostas na presente pesquisa não foram balizadas em qualquer trabalho anterior a respeito do tema comportamento do consumidor. A preocupação foi considerar que além do envolvimento no processo de compra, como fator que conduz à utilização do modelo de decisão de compra (PDC), as classes de produtos podem influenciar na não utilização de qualquer modelo. Por exemplo, de uma garrafa de água de $500 \mathrm{ml}$ enquadra-se na classe de produto de conveniência. Produtos dessa classe, comumente não são caros e demandam pouco esforço e tempo do consumidor para adquiri-los. E, conforme Oliveira e outros (2012), alguns estágios do processo de compra, como o de busca de informações e o de avaliação de alternativas podem ser suprimidos. Este fato pode descaracterizar a ideia de utilização de um modelo linear.

A Tabela 1 mostra as categorias de produtos classificada, a partir do maior percentual de escolha. A partir dela foi feita toda a análise da pesquisa e a verificação a respeito da adoção de um modelo linear de tomada de decisão de compra.

A base para a análise foram os trabalhos de Olshavsky e Branbois (1979) e Kassarjian (1978), como autores que se posicionam contrariamente à existência de um processo de decisão de compra (Modelo PDC) utilizado pelo consumidor confrontando-os com os trabalhos de autores que abordam a tomada de decisão a partir de uma perspectiva racional como forma de analisar as escolhas do consumidor, entre os quais se encontram Howard and Sheth (1969), Solomon (2002) e Blackwell e outros (2005).

TABELA 1 - Categorias de produtos

\begin{tabular}{|c|c|c|c|c|c|c|}
\hline \multirow{3}{*}{$\begin{array}{l}\text { Categoria de } \\
\text { Produto } \\
\text { Vestuário }\end{array}$} & \multicolumn{4}{|c|}{$\begin{array}{l}\text { Fi (frequência absoluta) e } \\
\text { percentual por gênero }\end{array}$} & \multirow{3}{*}{$\begin{array}{l}\begin{array}{l}\text { Fi } \\
\text { (frequência } \\
\text { relativa }\end{array} \\
\\
0,43\end{array}$} & \multirow{3}{*}{\begin{tabular}{|l}
$\begin{array}{l}\% \text { da Fi do } \\
\text { total }\end{array}$ \\
\\
$43 \%$
\end{tabular}} \\
\hline & \multicolumn{2}{|c|}{ Feminino } & \multicolumn{2}{|c|}{ Masculino } & & \\
\hline & 38 & $46 \%$ & 34 & $41 \%$ & & \\
\hline Higiene pessoal & 31 & $37 \%$ & 15 & $18 \%$ & 0,28 & $28 \%$ \\
\hline Alimentação & 6 & $7 \%$ & 13 & $16 \%$ & 0,11 & $11 \%$ \\
\hline Moradia & 1 & $1 \%$ & 5 & $6 \%$ & 0,04 & $4 \%$ \\
\hline Automóvel & 1 & $1 \%$ & 5 & $6 \%$ & 0,04 & $4 \%$ \\
\hline Outros & 6 & $7 \%$ & 11 & $13 \%$ & 0,10 & $10 \%$ \\
\hline Total & 83 & $100 \%$ & 83 & $\begin{array}{r}100 \\
\%\end{array}$ & 1,00 & $100 \%$ \\
\hline
\end{tabular}

Autores, entre os quais estão Schiffman e Kanuk (2 000), Mowen e Minor (2003) e Samara e Morsch (2005), concordam em relação ao fato de que o uso do modelo de decisão de compra é uma função do envolvimento do consumidor com a compra, isto é, quanto maior o envolvimento, maior a possibilidade de utilização de um processo linear.

A Tabela 2 resume a categoria de produto por grau de envolvimento, e está dividida pela classe do produto. Lembrando que o grau de envolvimento refere-se ao informado pelo respondente, uma vez que não estão estabelecidas nesta pesquisa as fronteiras de intensidade, isso por que qualquer valor sugerido esbarraria na singularidade do ser humano, pois o que é muito para um pode ser pouco para outro. $\mathrm{O}$ mesmo foi considerado no caso da divisão de classes de produtos. O creme dental que pode ser uma compra de conveniência para um indivíduo da classe média poderá ser uma compra comparada para um indivíduo de classe 
inferior. Esse aspecto foi esclarecido para os respondentes.

TABELA 2 - Categoria de produtos versus grau de envolvimento no processo de compra



No que concerne à intensidade de envolvimento do consumidor no processo de compra, a Tabela 2 demonstra que os produtos de conveniência apresentaram maior percentual de pleno envolvimento na compra do que o produto de compra comparada. Exceção foi feita para os produtos de especialidade, pois no questionário, a questão 1 referese a produtos adquiridos nos últimos trinta dias, o que não se mostrou apropriado para essa classe. Certamente, essas informações ainda são insuficientes para uma análise mais apurada do objetivo deste artigo, mas contribuíram para a construção do raciocínio pretendido pela pesquisa.

O comportamento motivado, que são atividades nas quais o indivíduo se empenha com foco em um objetivo e o envolvimento, que representa o grau de relevância de um objeto ou comportamento para um indivíduo, irá determinar a quantidade de esforço empreendido pelo consumidor no sentido de satisfazer as suas necessidades. O aumento do envolvimento do consumidor aumentará sua atenção às informações e ele estará disposto a ampliar o número de alternativas no processo de decisão. Assim, a análise dos resultados das questões de 3 a 6 ofertaram elementos em direção do amadurecimento da proposta do presente artigo (GADE, 1980; BLACKWELL et al., 2005).

Quando questionados a respeito da importância de s e obter informações a respeito do produto desejado, $84 \%$ afirmaram que sim. Esta informação tem forte convergência com a definição de envolvimento proposta por Sheth, Mitta 1 e Newman: "o grau de importância pessoal de um objeto ou produto ou serviço para um cliente" (SHETH; MITTAL; NEWMAN, 2001, p. 343). E, 16\% dos respondentes informaram que depende do produto, portanto, em determinadas situações o envolvimento no processo d e decisão de compra não será representativo ou mesmo não existirá. Um exemplo desta situação pode ser a compra de um jazigo, pois pertence à classe de produtos não procurados, consequentemente poderia não haver envolvimento. 
A importância da obtenção de informações é ratificada (questão 4) quando os respondentes são questionados a respeito do grau de intensidade que representa à suficiência em relação à quantidade e qualidade de informações obtidas, relativas ao produto que afirmaram ter adquirido nos últimos trinta dias, conforme a questão 1 do questionário. Do total, $83 \%$ afirmaram ser plenamente suficiente a quantidade e qualidade das informações obtidas.

Foi possível observar o efeito do envolvimento no processo de decisão de compra na quinta questão, quando $79 \%$ dos respondentes afirmaram ser importante a avaliação de alternativas disponíveis do produto desejado. Esse valor divergiu em apenas seis pontos percentuais para menos, quando na sexta questão foi solicitado aos respondentes que assinalassem o grau de intensidade de satisfação co $\mathrm{m}$ a quantidade e qualidade de alternativas obtidas para o produto adquirido. O percentual foi de $73 \%$.

A quantidade de informações obtidas a partir das $\mathrm{s}$ eis primeiras questões permite algumas considerações referentes ao objetivo da presente pesquisa que é obter elementos que permitam ratificar a posição dos autores que sustentam que o consumidor toma sua decisão de compra a partir de uma perspectiva racional ou ampliar a corrente dos que afirmam que os pesquisadores utilizam-se do antropomorfismo por atribuir um processo linear de escolha ao consumidor, mesmo em ocasiões que não ocorrem qualquer processo de escolha (SOLOMON, 2002; KASSARJIAN, 1978).

Para a amostra estabelecida nesta pesquisa foi possível verificar que o conceito de envolvimento fez-se presente de forma plena em $68,4 \%$ dos respondentes para a categoria alimentos. Não foi um percentual expressivo, e por se tratar de uma necessidade fisiológica pode ter ocorrido que o estímulo interno, em função das contrações características do estômago, tenha levado o indivíduo a ter um comportamento direcionado ao objetivo de diminuir a tensão que o afligia. Neste caso existe o comportamento motivado que conduzirá a busca até que o objetivo tenha sido alcançado ou até a intervenção de outra motivação (GADE, 1980).

O mesmo pode ser dito em relação ao produto de hig iene pessoal $(52,2 \%)$ e vestuário $(45,8 \%)$, pois não se tratou de percentuais expressivos. O que poderia justificar esses percentuais é o fato de se tratar de compras repetitivas, em que o grau de intensidade de envolvimento poderia ser o necessário.

Mas, a motivação pela busca de informações, situação em que o respondente se considerou plenamente suficiente $(83 \%)$ e a satisfação com as alternativas disponíveis, que foi de $73 \%$, configura-se, com base em Blackwell e outros (2005), Haword e Sheth (1969), entre outros, que ocorreu um processo de tomada de decisão racional, ou seja, foi seguido um roteiro.

A sétima questão procurou aprofundar-se na definição de envolvimento, com a finalidade de verificar se existia alguma variável que fosse crucial na tomada de decisão de compra do consumidor. Para isso, foram apresentados cinco itens (informações, alternativas, preço, disponibilidade e tempo de entrega) para que o respondente assinalasse aquele que julgava o mais importante em sua decisão de compra e que tenha sido válido para o produto apontado por ele na primeira questão do questionário.

O resultado aponta para o preço $(58 \%)$ como a variável mais importante para a tomada de decisão de compra da amostra pesquisada (17\% informações, $11 \%$ tempo de entrega, $8 \%$ alternativas e $6 \%$ disponibilidade). O preço, portanto, demonstrou ser o motivador do processo de decisão de compra. Este fato pode justificar o interesse por informações e alternativas do produto desejado, o que ratificou para a amostra pesquisada a utilização de um roteiro racional.

Em função dos resultados obtidos a partir das sete questões anteriores, a oitava e a nona questão foram cruciais para os objetivos da pesquisa, pois a pretensão foi, por meio delas, verificar se os respondentes reconheciam a utilização de um modelo racional ou por se tratar de compras repetitivas, o processo sequer existia. Para isso, foram questionados se, para o produto mencionado na primeira questão, utilizara $\mathrm{m}$ algum roteiro (oitava questão), 
e, se sim, foi solicitado que descrevesse com a maior riqueza de detalhes possível o referido roteiro (nona questão).

A Tabela 3 apresenta os resultados da oitava questão. Nela é possível verificar que a maioria dos respondentes afirmou não utilizar um roteiro previamente estabelecido para efetuar suas compras, e nem para o produto adquirido. Contudo, tal afirmação, isoladamente, não permite determinar que eles não utilizaram o roteiro, mesmo que inconscientemente ou que nunca atentaram ao fato de que os procedimentos, muitas vezes mecanizados, realizados por eles, são considerados pelos pesquisadores como um roteiro racional. Assim, sendo seria ratificada a posição de antropomorfismo sustentada por Kassarjian (1978) e Olshavsky e Granbois (1979).

\section{Tabela 3}

\section{A existência de roteiro previamente elaborado para a compra do produto mencionado na questão 1 do questionário}

\begin{tabular}{|l|l|l|}
\hline & Freq abs. (Fi) & $(\mathbf{\%})$ \\
\hline Sim & 39 & $23 \%$ \\
\hline Não & 88 & $53 \%$ \\
\hline $\begin{array}{l}\text { Depende do } \\
\text { produto }\end{array}$ & 39 & $23 \%$ \\
\hline Total & $\mathbf{1 6 6}$ & $\mathbf{1 0 0 \%}$ \\
\hline
\end{tabular}

Dizer que os consumidores passam por estágios quando tomam decisões é ponto de convergência entre autores que abordagem o comportamento do consumidor. Quanto aos estágios podem ser cinco conforme Kotler e Armstrong (2003) e Solomon (2002); podem ser seis, de acordo com Samara e Morsch (2005); podem ser complexos como os propostos por Nicosia (1966); Haword e Sheth (1969) e Blackwell e outros (2005). Também, conforme Oliveira e outros (2012), independentemente do número de estágios, alguns deles podem ser suprimidos. É nesse ponto que a nona questão está balizada, ou seja, qual a quantidade mínima para que se reconheça um processo racional d e tomada de decisão de compra?

Para Gade, "cada indivíduo tem certas formas de comportamento e respostas próprias e únicas em que parte se remete à sua estrutura de personalidade." (GADE, 1980, p. 13) Apesar de sua unicidade, o indivíduo não está isento de seguir processos ordenados e racionais, como os estágios dos modelos de decisão. E a autora explica esses estágios a partir da perspectiva psicológica. Desta maneira, o processo de decisão seria uma condição para a satisfação das necessidades e desejos do consumidor .

Nessa ordenação realizada por Gade (1980), alguns estágios não têm como serem suprimidos, pois do contrário não haveria a tomada de decisão. Apesar de não apontá-los, a autora afirma que o reconhecimento do problema (necessidade ou desejo) comumente é o primeiro passo do processo decisório. De maneira resumida, os demais estágios seriam: a busca de informação; procura de alternativas; avaliação de alternativas e a compra. Mas, numa primeira compra não é necessário que se passe por todos esses estágios, com exceção do primeiro, o reconhecimento do problema. Isso porque o indivíduo poderá comprar por impulso ou por interesse na experiência, considerando os riscos inerentes ao processo, pois agir desta forma na compra de uma casa condenada não seria um processo racional.

Outros dois aspectos devem ser considerados: primeiro: nas compras repetitivas esse processo poderá não existir por se tratar, por exemplo, de reposição como a compra de um galão de água com vinte litros. Segundo: as empresa, na disputa por espaço no mercado trabalham incessantemente por alternativas para manipular a percepção do consumidor criando um estado de desconforto que resulte na aquisição de seus produtos. Neste momento, as empresas estariam fazendo uso do antropomorfismo.

Feitas essas considerações, o autor do presente artigo considerou que um processo de decisão deverá ter no mínimo dois estágios, que são: reconhecimento da necessidade ou 
desejo e o ato da compra. Assim, partindo dessa perspectiva, na nona questão, dos 39 respondentes que afirmaram seguir algum roteiro, apenas 24 apresentaram, os 15 restantes nada apresentaram. Dentre esses 24 modelos, apenas 15 foram considerados válidos por apresentarem, no mínimo, os dois estágios necessários para serem considerados como um modelo. Dentre os 15 modelos válidos, apenas dois mencionou cinco estágios, os demais alternavam entre 2, 3 e 4 estágios.

\section{6 - CONCLUSÕES OBTIDAS}

Para a amostra pesquisada, mediante os dados obtidos e as bases teóricas e empíricas dos autores consultados percebeu-se que:

1. Toda compra apresenta um roteiro, mas não necessariamente com números de estágios definidos ou sequenciais, com exceção de dois: o re conhecimento da necessidade ou desejo e a compra. O primeiro poderá não evoluir e até mesmo ser substituído por outro com maior motivação, mas afirmar que o processo ocorreu dependerá, no mínimo desses dois estágios;

2. Nas compras repetitivas de produtos de reposição (creme dental, fio dental, água em galão etc.) poderá não haver a passagem por todos os estágios, mas no mínimo os dois citados no item 1 ;

3. Para a amostra pesquisada os percentuais que apontavam para a utilização de modelos (Tabela 3), não confirmam a inexistência de um processo;

4. É fato que a disputa pela mente do consumidor, por parte das empresas, as leva a praticar o antropomorfismo, mas daí afirmar que não existe um processo envolvendo no mínimo dois estágios para a efetivação da compra, ficou comprovado pela presente pesquisa. Os fatos de 15 respondentes não terem apresentado seus modelos não comprova a sua inexistência, pois eles efetuaram a compra de um produto, portanto, no mínimo ocorreram dois estágios.

5. Finalmente, a amostra pesquisada não ratifica a posição de Kassarjian (1978) Olshavsky e Granbois (1979), de que em certos momentos inexiste a utilização de um modelo, pois se assim for a compra não teria ocorri do e as argumentações não teriam

razão de ser. É certo que o antropomorfismo existe, mas não isenta o consumidor de um processo de tomada de decisão com no mínimo dois estágios. Todavia, esse processo não é rígido e com um trajeto obrigatório.

\section{Considerações finais}

A presente pesquisa teve como principal objetivo obter elementos que contribuíssem com o campo de conhecimento do comportamento do consumidor, especificamente, no que se refere ao processo de tomada de decisão de compra do consumidor. Foram confrontadas as posições de autores que compreendem o processo de decisão a partir de uma perspectiva racional e autores que sustentam que em certas compras não há, e nunca houve necessidade de se seguir quaisquer estágios. A amostra utilizada na presente pesquisa ofertou elementos que permitiu contribuir para o debate proposto neste artigo, de maneira que foi possível afirmar que o processo de decisão do consumidor é inerente à personalidade do indivíduo e, embora suas respostas possam ser impares e suas compras sejam, por exemplo, uma recompra; uma compra nova; ou uma compra modificada, no mínimo dois estágios serão necessários para a realização desse processo, que são: o reconhecimento da necessidade ou desejo e o ato da compra. Também, que diferentemente do que possam parecer, os estágios não são rígidos, mas antes uma consequência do comportamento humano de equilibrar suas necessidades e desejos a partir do alcance de objetivos que resolva a discrepância entre um determinado estado atual e o estado desejado. 
Certamente, esta pesquisa não esgota os debates a respeito do tema abordado. Limitações existiram, dentre as quais: o tamanho da amostra, a área pesquisada, os produtos considerados na pesquisa e a necessidade de se confrontar mais de um produto por categoria, no sentido de analisar as possíveis tipologias de consumidor no processo de decisão de compra. Contudo, o autor espera que esta pesquisa motive os interessados no assunto a aprofundar o debate ou derivar outros temas a partir dela.

\section{REFERÊNCIAS}

BLACKWELL, Roger D.; MINIARD, Paul W.; ENGEL, James F. Comportamento do consumidor. São Paulo: Pioneira Thomson Learning, 2005.

CASTELLS, M. A sociedade em rede. 6. ed. São Paulo: Paz e Terra, 2002. v. 1.

CERVO, Amado L.; BERVIAN, Pedro A.; SILVA, Roberto da. Metodologia científica. 6. ed. São Paulo: Pearson Prentice Hall, 2005.

DETRITOS jogados nas ruas entopem bueiros e bocas de lobo em São Paulo. Folha.com., 2010. Disponível em: <http://www1.folha.uol.com.br/saopaulo/825047-detritos-jogados-nasruas-entopem-bueiros-e-bocas-de-lobo-em-sao-paulo.shtml>. Acesso em: 13 jan. 2012.

FUNDAÇÃO DE PROTEÇÃO E DEFESA DO CONSUMIDOR. Histórico institucional no Brasil. Disponível em: <http://www.procon.sp.gov.br/texto.asp?id=1146>. Acesso em: 8 fev. 2012.

GADE, Christiane. Psicologia do consumidor. São Paulo: EPU, 1980.

GIGLIO, Ernesto M. O comportamento do consumidor. 2. ed. rev. e ampl. São Paulo: Pioneira Thonson Learning, 2003.

HAIR, Joseph F. et alii. Fundamentos de métodos de pesquisa em administração . Porto Alegre: Bookman, 2005.

HOFFMAN, K. Douglas; BATESON, John E. G. Princípios de marketing de services: conceitos, estratégias e casos. São Paulo: Pioneira Thomson Learning, 2003.

HOWARD, John A.; SHETH, Jagdish N. The theory of buyer behavior. New York: John Wily \& Sons, 1969.

INSTITUTO BRASILEIRO DE GEOGRAFIA E ESTATÍSTICA. Orçamento familiar (POF) 2008-2009. 2012. Disponível em: <http://www.ibge.gov.br/home/estatistica/populacao/condicaodevida/pof/2008_2009/POFpu b licacao.pdf.>. Acesso em: 10 fev. 2012.

KARSAKLIAN, E. Comportamento do consumidor. 2. ed. São Paulo: Atlas, 2008.

KASSARJIAN, Harold H. Presidential address, 1977: anthropomorphism and parsimony. Advances in Consumer Research, n. 5, p. xiii-xiv, 1978.

KOTLER, P.; ARMSTRONG, G. Princípios de marketing. 9. ed. São Paulo: Prentice Hall, 2003.

LAWSON, R. Consumer decision making within a goal-driven framework. Psychology \& 
Marketing, v. 14, n. 5, p. 427-449, 1997.

LIMEIRA, Tania Maria V. Comportamento do consumidor. São Paulo: Saraiva, 2008..

MARTINS, Gilberto de Andrade; DONAIRE, D. Princípios de estatística. São Paulo: Atlas, 1988.

MOWEN, John C.; MINOR, Michael S. Comportamento do consumidor. São Paulo: Prentice-Hall, 2003.

MUNCY, James A.; HUNT, Shelby D. Consumer involvement: definitional issues and research directions. Advances in consumer research, v. 11, p. 193-196, 1984.

NÉRICI, Imídeo Giuseppe. Introdução à lógica . 5. ed. São Paulo: Nobel, 1978.

NICOSIA, Francesco M. Consumer decision processes: marketing and advertising implications. Englewood Cliffs, New Jersey: Prentice-Hall, 1966.

OLIVEIRA, Braulio et alii. Gestão de marketing . São Paulo: Pearson Prentice Hall, 2012.

OLSHAVSKY, Richard W.; GRANBOIS, Donald H. Consumer decision making: fact or fiction? Journal of Consumer Research v. 6, p. 93-100, 1979.

SAMARA, Beatriz S.; MORSCH, Marco A. Comportamento do consumidor: conceitos e casos. São Paulo: Pearson Prentice Hall, 2005.

SHETH, Jagdish N.; MITTAL, Banwari; NEWMAN, Bruce I. Comportamento do cliente: indo além do comportamento do consumidor. São Paulo: Atlas, 2001.

SCHIFFMAN, Leon G.; KANUK, Leslie L. Comportamento do consumidor. 6. ed. Rio de Janeiro: LTC, 2000.

SOLOMON, Michael R. O comportamento do consumidor: comprando, possuindo e sendo. Porto Alegre: Bookman, 2002.

VOLPI, A.; MEIER, R. A história do consumo no Brasil : do mercantilismo à era do foco no cliente. Rio de Janeiro: Elsevier, 2007. 